\title{
Characteristics of European hare Lepus europaeus use of space in a French agricultural region of intensive farming
}

\author{
François REITZ and Yves LÉONARD
}

\begin{abstract}
Reitz F. and Léonard Y. 1994. Characteristics of European hare Lepus europaeus use of space in a French agricultural region of intensive farming. Acta theriol. 39: 143-157.

Fifty-one European hares Lepus europaeus Pallas, 1778 were monitored during at least one month by radiotracking in an intensively farmed landscape. The mean home range size of 21 hares monitored during at least six months was about 100 ha. During summer and autumn, seasonal home range size and the mean distance between fixes did not reveal any difference in the use of space between sexes or between age classes. However, according to the shifts of monthly resting range centres, females seemed to be more sedentary than males. The night-time activity range was often larger than the daytime resting range and partly or totally overlapped it although resting and activity locations were rarely the same. Hare movements did not show any important changes in response to crop harvesting or shooting.

Office National de la Chasse, Saint Benoist, 78610 Auffargis, France

Key words: Lepus europaeus, home range, radiotracking, harvesting effect, shooting effect
\end{abstract}

\section{Introduction}

As has been suggested by Tapper and Barnes (1983), in England intensive farming practices are likely to have a limiting effect on the dynamics of European hare Lepus europaeus Pallas, 1778 populations. The positive effects of habitat improvements shown by Slamecka (1991) seem to comfirm this assumption. An indirect indication of the poor quality of this type of habitat for hares could be a change in their spatial pattern of movement.

Little research has been conducted on European hare use of space. The earliest home range study is by Pielowski (1972) in Poland, who estimated a mean home range of 300 ha using empirical methods. More recent studies have used radiotracking techniques (Broekhuizen and Maaskamp 1982, Parkes 1984, Tapper and Barnes 1986, Kovacs and Buza 1988), which all reported quite similar range sizes. Unfortunately, methods of radiotracking and data analysis have varied and, except for Parkes (1984) who tracked five hares for one year, most of the animals were tracked for periods that were short but of variable length, mainly at the end of 
summer and in autumn. Therefore no evident general pattern of use of space by hares can be drawn from the already published radiotracking results. On the other hand, none of these studies took place in an intensively farmed landscape like that found in several regions of France. Studies on the use of space by the European hare in France have only concerned adults or leverets released into less-intensively farmed regions (Ricci 1983, Pepin and Cargnelutti 1985, 1987, Marboutin et al. 1991).

In order to improve our knowledge of hare behaviour and dynamics in one of the most intensively farmed regions of France, we conducted a study there. One of our goals was to determine the general characteristics of hare use of space in this type of habitat and especially to detect potential alterations in their behaviour in reference to other studies and by an analysis of variations over time in relation to human activities. In this respect, we decided to study several characteristics of the use of space: home range size, relative positions of resting and activity places and the successive locations of short-period range centres as an index of home range spatial stability.

\section{Material and methods}

The study area is a shooting estate of $20 \mathrm{~km}^{2}$ located $50 \mathrm{~km}$ north-west of Paris. The landscape is flat with little undulations and is characterized by the absence of hedges, few woods, except for the wooded valleys bordering the area at the east. The soil is a deep limon. The climate is oceanic with continental tendencies. Mean temperature are $3-4^{\circ} \mathrm{C}$ in winter and $17-18^{\circ} \mathrm{C}$ in summer. Average field size is approximately 10 ha. Crops are, in decreasing order of importance: wheat $(47 \%$ of the cultivated area in 1989$)$, sugar beets $(19 \%)$, peas $(11 \%)$, maize $(5 \%)$, potatoes (4\%), French beans (4\%), alfalfa $(3 \%)$, and oilseed rape $(1 \%)$. Farming practices are so intensive that, for example, yields of wheat may exceed 10 tonnes/ha. The hare population density, estimated by spotlight counts (Barnes and Tapper 1985) and strip censuses (Pepin and Birkan 1981), was between 10 and 20 hares $/ \mathrm{km}^{2}$ in early spring. Hares are shot from the end of September to the beginning of December by hunters walking in line or being posted. Some parts of the area were not hunted.

In 1989, hares were captured in June and, in 1990, during January and from May to August. Hares were caught in unbaited cage-traps set in the middle of unsown fields or in fields where crops were still low. Hares were radiocollared with Biotrack or Wagener transmitters weighing about $30 \mathrm{~g}$. Only adult hares and juveniles weighing more than 1500 g, i.e. about eight weeks old or over (Pepin 1973), were collared. We considered as young of the year those animals that showed a knob at the distal epiphysis of the ulna by palpation through the skin (Walhovd 1966, Broekhuizen and Maaskamp 1979). All other animals were classified as adults. A total of 51 hares were marked and tracked for at least one month (adults: 13 males and 14 females, young of the year: 12 males and 12 females).

Totally, 6760 locations were obtained using Yaesu 290R radio-receivers (Yaesu Musen Co, Ltd, Japan), one omnidirectional whip antenna and one three-, four- or five-element Yagi aerial mounted on a vehicle $3 \mathrm{~m}$ above ground level. Two or three non-synchronous bearings were taken from the corners of the field wherein the animal was situated. We estimated the precision of this tracking system at a range of $100 \mathrm{~m}$ by flushing a few radiolocated animals. Therefore, the fixes were centred within $100 \times 100 \mathrm{~m}$ grid squares for analysis. Usually animals were located at random once per $24 \mathrm{~h}$, two nights per week during the harvest period and one night per week during the shooting period (see description of the tracking periods below). 
Radiotracking data were analysed using Ranges IV package (Kenward 1990). Home range areas were calculated using the minimum convex polygon method (MCP) (Mohr 1947). No home range was calculated with fewer than 15 fixes nor when the animal could not regularly be located because of a defective transmitter. For longer time periods we used two other methods. The first one, the Kernel smoothing method proposed by Worton (1989) determines a utilization distribution of the home range with greater accuracy, according to Kenward (1990), than the more commonly used harmonic mean analysis method established by Dixon and Chapman (1980). We also used the Dixon and Chapman method in order to compare our results to those of Tapper and Barnes (1986). It was also used to determine range centres. Both methods allow to delimit core areas, i.e. areas where the animals are supposed to spend a definite proportion of their time with respect to the spatial distribution of fixes.

Patterns of space use were also examined through: (1) the mean distance between daytime locations of two successive days - day-day distance (DDD), (2) the mean distance between one daytime location and a location the following night - day-night distance (DND), (3) the percentage of night fixes included in the resting range, i.e. the range determined by daytime locations only, (4) when the activity range could be determined (with the only night-time locations), the percentage of day fixes included in it, (5) the distance between centres of successive resting ranges, (6) the distance between simultaneous resting and activity range centres. The mean DDD and DND were analysed only for animals for which at least five distances could be averaged.

Four time scales were used to analyse the data: by month (from the 16th of each month), by season (harvest period before shooting from July 16 to September 30, and the shooting period from 1 October to 15 December), by half-year (summer-autumn or autumn-winter) and the whole period of monitoring for hares that had been radiotracked during 9 to 10 months. Monthly analyses could not be performed for the early winter period because of lack of data (fewer than 15 fixes per hare/month).

All analyses were conducted using SPSS PC+ statistical package. DDD and DND were normalized by square root transformation (Sokal and Rohlf 1981) to allow comparisons using parametric tests. Home range sizes that could not easily be normalized were compared using non parametric tests. Multiple paired-tests were used instead of ANOVA-like analyses in order to cope with the lack of independence of data successively or simultaneously recorded on one animal and with variations among radiotracked animals (staggered entry and leaving designs).

\section{Results}

\section{Effect of sex and age on use of space}

Seven characteristics of use of space were studied: for the harvest period, these included the resting (daytime) and activity (night-time) range areas (MCP method) and the mean DDD and DND. For the shooting period, the same variables were analysed except for the activity range size (not enough data). None of them varied significantly between sex and age classes (Table 1). Moreover, the actual but not significant variations of the home range size between age or sex groups were most often not confirmed by comparing mean distances between fixes, which varied in a different manner. One exception is for the young females that seem to have had more restricted resting areas in summer than other animals and particularly young males.

\section{Characteristics of home ranges over a long period}

Six hares were regularly tracked for more than 9 months from June to March. Using all day and night fixes we calculated their total home range, using MCP 
Table 1. Variations in range sizes (MCP method), in mean distances between two successive-day resting places (DDD) and in mean distances between a resting place and a subsequent night location (DND). None statistical analysis (Kruskal-Wallis and Mann-Whitney $U$-tests for range sizes and analyses of variance on square roots for distances) gives significant results.

\begin{tabular}{|c|c|c|c|c|}
\hline Characteristic & $\begin{array}{c}\text { Young males } \\
\text { mean } \pm \mathrm{SD}\end{array}$ & $\begin{array}{c}\text { Young females } \\
\text { mean } \pm \mathrm{SD}\end{array}$ & $\begin{array}{c}\text { Adult males } \\
\text { mean } \pm \text { SD }\end{array}$ & $\begin{array}{c}\text { Adult females } \\
\text { mean } \pm \text { SD }\end{array}$ \\
\hline \multicolumn{5}{|l|}{ Harvest period (16/07-30/09) } \\
\hline Resting (day) range (ha) & $\begin{array}{c}61 \pm 42 \\
n=6\end{array}$ & $\begin{aligned} 31 & \pm 15 \\
n & =6\end{aligned}$ & $\begin{aligned} 46 & \pm 18 \\
n & =8\end{aligned}$ & $\begin{array}{c}43 \pm 26 \\
n=4\end{array}$ \\
\hline $\mathrm{DDD}(\mathrm{m})$ & $\begin{aligned} 178 & \pm 80 \\
n & =6\end{aligned}$ & $\begin{aligned} 117 & \pm 53 \\
n & =6\end{aligned}$ & $\begin{array}{c}168 \pm 76 \\
n=8\end{array}$ & $\begin{aligned} 151 & \pm 41 \\
n & =4\end{aligned}$ \\
\hline Activity (night) range (ha) & $\begin{array}{c}66 \pm 30 \\
n=6\end{array}$ & $\begin{aligned} 56 & \pm 38 \\
n & =6\end{aligned}$ & $\begin{aligned} 53 & \pm 22 \\
n & =8\end{aligned}$ & $\begin{array}{c}77 \pm 54 \\
n=4\end{array}$ \\
\hline $\mathrm{DND}(\mathrm{m})$ & $\begin{aligned} 290 & \pm 81 \\
n & =6\end{aligned}$ & $\begin{aligned} 269 & \pm 42 \\
n & =6\end{aligned}$ & $\begin{aligned} 318 & \pm 108 \\
n & =8\end{aligned}$ & $\begin{array}{c}283 \pm 50 \\
n=4\end{array}$ \\
\hline \multicolumn{5}{|l|}{ Shooting period $(01 / 10-15 / 12)$} \\
\hline Resting (day) range (ha) & $\begin{array}{c}71 \pm 62 \\
n=8\end{array}$ & $\begin{aligned} 79 & \pm 56 \\
n & =6\end{aligned}$ & $\begin{aligned} 54 & \pm 34 \\
n & =7\end{aligned}$ & $\begin{aligned} 53 & \pm 17 \\
n & =3\end{aligned}$ \\
\hline $\operatorname{DDD}(\mathrm{m})$ & $\begin{array}{c}174 \pm 61 \\
n=8\end{array}$ & $\begin{array}{c}177 \pm 64 \\
n=6\end{array}$ & $\begin{aligned} 167 & \pm 37 \\
n & =7\end{aligned}$ & $\begin{aligned} 186 & \pm 26 \\
n & =3\end{aligned}$ \\
\hline $\mathrm{DND}(\mathrm{m})$ & $\begin{array}{c}401 \pm 71 \\
n=5\end{array}$ & $\begin{array}{c}386 \pm 109 \\
n=4\end{array}$ & $\begin{array}{c}420 \pm 104 \\
n=4\end{array}$ & $\begin{aligned} 397 & \pm 253 \\
n & =3\end{aligned}$ \\
\hline
\end{tabular}

and Kernel smoothing methods of analysis (Table 2). The average home range area obtained by the Kernel method when including $100 \%$ of the fixes (Kernel-100\%) is close to the mean value obtained by MCP: both methods give a mean size of slightly more than 100 ha. However, these averages mask large discrepancies: as shown by the standard deviation and minimum and maximum values, the areas estimated by one method differed greatly from one animal to another. For a single animal the estimates of the home range size by both methods could also differ much: e.g. 118 ha for female no. 439 by MCP and 49 ha by Kernel-100\%.

Excluding the outermost fixes gives a more accurate view of the areas well-frequented by hares. When $5 \%$ of the fixes are excluded, the mean home range size obtained by the Kernel smoothing method (Kernel-95\%) is half of the Kernel-100\% (54 ha). The method used by Tapper and Barnes (1986) - 10\% outermost fixes excluded in a harmonic mean analysis - leads to a mean home range size of 38 ha.

Six-month home range sizes could be determined for the same hares and for fifteen others, eight in summer and autumn, and seven in autumn and winter. They were quite similar to the 9-10 month ranges, whatever the period or method used (Table 2). This apparent stability of home range size after six months can be tested using an analysis that does not give an increasing range with increased 
Table 2. Descriptive statistics of total home range sizes (ha) of 21 hares tracked over a long period. ${ }^{\text {a }}$ including the six hares tracked over 9-10 months.

\begin{tabular}{|c|c|c|c|c|c|}
\hline \multirow[t]{2}{*}{ Period } & \multirow{2}{*}{$\begin{array}{c}\text { Number } \\
\text { of home } \\
\text { ranges }\end{array}$} & \multirow[t]{2}{*}{$\begin{array}{l}\text { Stati- } \\
\text { stics }\end{array}$} & \multirow[t]{2}{*}{$\begin{array}{c}\text { MCP } \\
\text { analysis }\end{array}$} & \multicolumn{2}{|c|}{$\begin{array}{c}\text { Kernel smoothing } \\
\text { method analysis }\end{array}$} \\
\hline & & & & $100 \%$ fixes & $95 \%$ fixes \\
\hline \multirow[t]{4}{*}{ 9-10 months } & 6 & mean & 123 & 109 & 54 \\
\hline & & SD & 74 & 101 & 37 \\
\hline & & $\min$ & 70 & 49 & 30 \\
\hline & & $\max$ & 268 & 308 & 127 \\
\hline 6 months & $14^{\mathrm{a}}$ & mean & 109 & 111 & 60 \\
\hline \multirow[t]{3}{*}{ summer and autumn } & & SD & 54 & 78 & 31 \\
\hline & & $\min$ & 66 & 40 & 27 \\
\hline & & $\max$ & 225 & 304 & 122 \\
\hline 6 months & $13^{\mathrm{a}}$ & mean & 110 & 85 & 50 \\
\hline \multirow[t]{3}{*}{ autumn and winter } & & $\mathrm{SD}$ & 69 & 77 & 39 \\
\hline & & $\min$ & 39 & 31 & 19 \\
\hline & & $\max$ & 295 & 319 & 173 \\
\hline
\end{tabular}

Table 3. Changes in home range sizes (ha) of 14 hares as a function of length of time they were monitored (Kernel smoothing method, with $95 \%$ of fixes). The number of fixes used in each case is in brackets. ${ }^{a}$ mean range size and number of fixes for the only hares monitored during 9-10 months.

\begin{tabular}{|c|c|c|c|c|}
\hline $\begin{array}{l}\text { Identification } \\
\text { number of animals } \\
\text { (sex and age) }\end{array}$ & $\begin{array}{c}2.5 \text { months } \\
\text { (harvest period } \\
\text { before shooting) }\end{array}$ & $\begin{array}{c}6 \text { months } \\
\text { (summer and } \\
\text { autumn) }\end{array}$ & & $\begin{array}{c}9-10 \text { months } \\
\text { (total monitoring } \\
\text { period) }\end{array}$ \\
\hline 345 (M ad) & $36 \quad(94)$ & 36 (158) & & - \\
\hline 385 ( $\mathrm{F}$ juv) & 27 (93) & 40 (177) & & - \\
\hline $461(\mathrm{M} \mathrm{ad})$ & $25 \quad(75)$ & 44 (167) & & - \\
\hline 380 (M juv) & $41(102)$ & 44 (184) & & - \\
\hline $388(\mathrm{M}$ ad $)$ & $24 \quad(94)$ & 61 (191) & & - \\
\hline 394 ( $\mathrm{F}$ juv) & $20 \quad(97)$ & $94(200)$ & & - \\
\hline $386(\mathrm{M}$ ad $)$ & $75 \quad(92)$ & 99 (180) & & - \\
\hline 393 (M juv) & 115 & $122(164)$ & & - \\
\hline 434 (M juv) & 18 & 31 (186) & & 30 (225) \\
\hline $439(\mathrm{~F} \mathrm{ad})$ & 13 & 27 (191) & & 33 (237) \\
\hline $429(\mathrm{M}$ ad $)$ & $32 \quad(71)$ & 35 (183) & & 38 (227) \\
\hline $450(\mathrm{M}$ ad $)$ & $42 \quad(69)$ & 45 (172) & & 40 (196) \\
\hline 447 (M juv) & $44 \quad(70)$ & $56(180)$ & & $58(213)$ \\
\hline 396 (M juv) & $98 \quad(87)$ & $104(175)$ & & $127(228)$ \\
\hline Mean & $44 \quad(84)$ & 60 (179) & {$[50(181)]^{\mathrm{a}}$} & $54(221)$ \\
\hline
\end{tabular}


numbers of fixes (Kernel-95\%). The mean home range size of six animals that were monitored for more than six months increased slightly but not significantly from the summer-autumn six-months period to the whole monitoring period (Table 3). However home range sizes tend to be smaller over a shorter period, e.g. during the harvest season (2.5 months from 16 July to 30 September) (Wilcoxon test, $n$ $=14, p<0.01$ ). This means that estimating home range based on short periods of a few months gives a poor estimate of a total home range.

\section{Comparison between day and night use of space}

Day and night home ranges were computed separately for the harvest period. The day home range was significantly smaller than the night range, 46 ha $\pm 6 \mathrm{SE}$, $n=24$, (with 61 fixes per hare on average, MCP method) and 61 ha $\pm 7 \mathrm{SE}, n=$ 24 , (with 25 fixes) respectively (Wilcoxon test, $n=24, p=0.01$ ). Examining distances between fixes, we obtained similar results (Table 4): for the whole period of crop harvesting before the beginning of shooting, the mean DND was twice the mean DDD. These data illustrate the tendency of hares to move far from their resting place at night and then to come back near their previous form (e.g. Fig. 1). In only one case out of four, was a hare located in the same field during one day and the following night (mean DND of $125 \mathrm{~m}$ ). In fewer than 6\% of cases was a hare situated in the same grid square one day and the next night. During the same period, the centres of day and night ranges were not identical and the mean distance between them was $260 \mathrm{~m}$. But this does not mean that these ranges were well separated: on average $71 \%$ of the night fixes were included in the day home range while $86 \%$ of the day fixes were included in the night range. In half of the

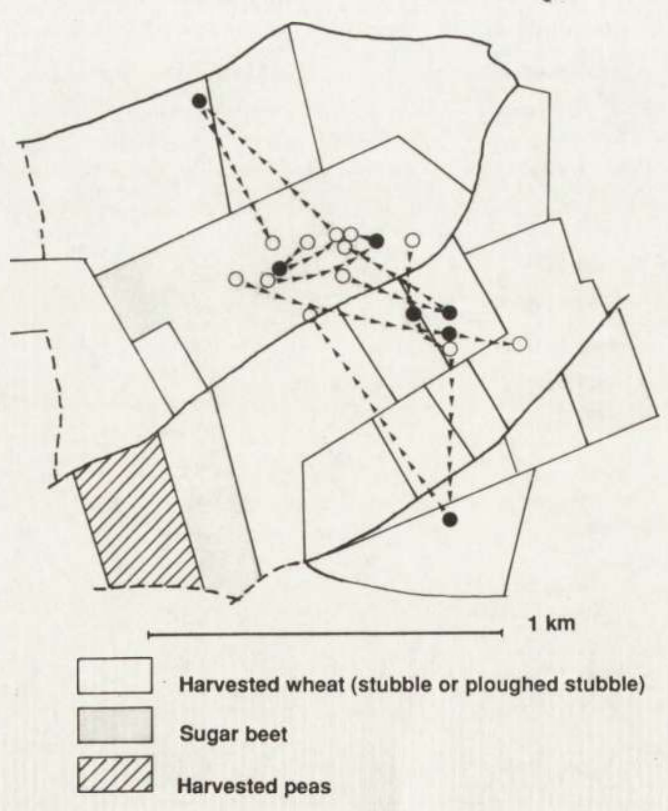

Fig. 1. Day-to-the-next-night and to-the-next-day courses measured from 16 August to 15 September for one hare. The locations (open circles - by day, dark circles - by night) are centred in the grid squares. 
cases, this latter proportion was greater than $90 \%$. Only two hares had relatively distinct day and night ranges with fewer than $60 \%$ day fixes included in the night range. Fig. 2 illustrates two patterns that were most common: day and night ranges of approximately the same size generally overlapping in a varying proportion, or the day range smaller than the night range and entirely or almost entirely included in it.

Within the harvest period, some changes in the behaviour of hares are revealed by our data. If the DND did not vary significantly between the cereal harvesting month (from 16 July to 15 August) and the following one (Table 4), there was a large variation in the overlap of night fixes and day home ranges: $72 \%$ of the night fixes were included in the day home range during the cereal-harvesting month while in the next month this percentage dropped to $50 \%$ (Wilcoxon test, $n=14$, $p<0.05$ ). Thus, even if hares did not travel farther for their night activity after the cereal harvest, they seemed to have used more distinct activity and resting places following the rapid transformation of their habitat.

Insufficient data were available to determine night ranges for the shooting period but a study of the other parameters suggests that hares had a quite similar behaviour before and during the shooting period. For example, the mean percentages of night fixes included in the day home range were similar $(71 \%$ before and $72 \%$ during the shooting period) and the mean DDD did not vary significantly between these periods (Table 4). The mean DND was somewhat larger during the shooting period but the difference is not significant if we study the only hares for which both distances were recorded. On the other hand, there was still a highly significant difference between the mean DDD and DND during the shooting period.
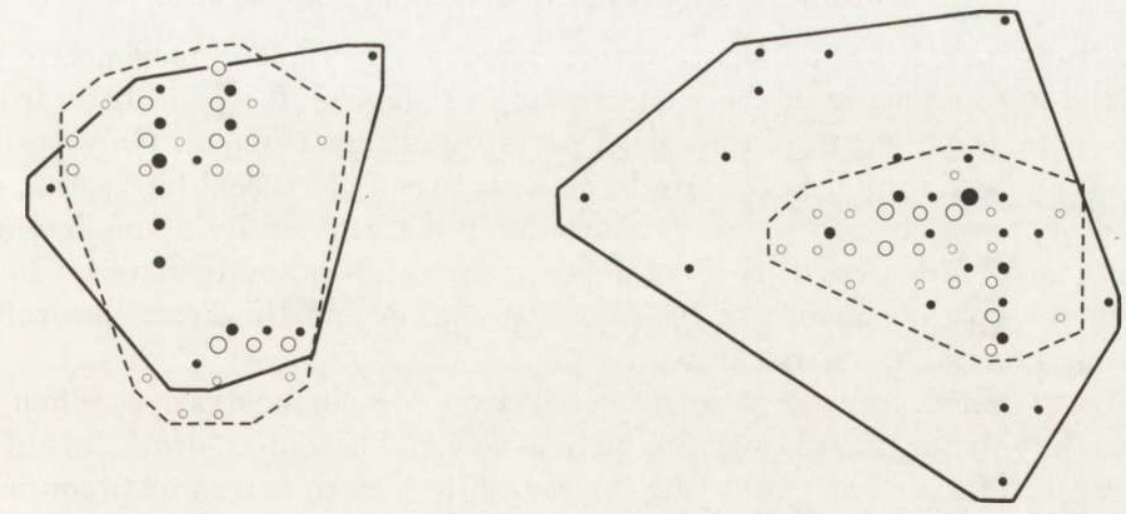

$1 \mathrm{~km}$

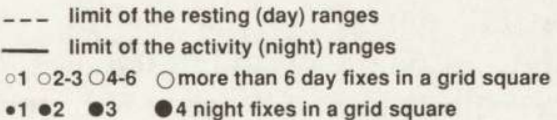

Fig. 2. Two major patterns of space use by hare during the harvesting period (16 July-30 September). Distribution of the day and night locations and corresponding ranges (MCP method). 
Table 4. Statistical analysis of the variations, by period and month within the crop harvesting period, of two interfix distances during summer and autumn: the mean $( \pm S D)$ distance between two resting places located on two successive days (DDD) and the mean $( \pm$ SD) distance between a resting place and an activity place located during the subsequent night (DND), $n$ - number of animals concerned. Statistics are the Student paired $t$-test of the mean distances transformed into square roots.

\begin{tabular}{|c|c|c|c|}
\hline & $\begin{array}{l}\text { DDD } \\
(\mathrm{m})\end{array}$ & $\begin{array}{c}\text { DND } \\
(\mathrm{m})\end{array}$ & $\begin{array}{l}\text { DDD vs DND } \\
\text { statistics }\end{array}$ \\
\hline $\begin{array}{l}\text { Crop harvesting before } \\
\text { shooting period } \\
\text { (16 July-30 September) }\end{array}$ & $\begin{array}{r}155 \pm 67 \\
n=24\end{array}$ & $\begin{array}{r}293 \pm 78 \\
n=24\end{array}$ & $t=9.50, \mathrm{df}=23, p<0.001$ \\
\hline $\begin{array}{l}\text { Shooting period } \\
\text { (1 October-15 December) }\end{array}$ & $\begin{array}{r}174 \pm 50 \\
n=24\end{array}$ & $\begin{array}{c}401 \pm 121 \\
n=16\end{array}$ & $t=9.02, \mathrm{df}=15, p<0.001$ \\
\hline Between-period statistics & $t=0.13, \mathrm{df}=13, p=0.90$ & $t=1.60, \mathrm{df}=5, p=0.17$ & \\
\hline $\begin{array}{l}\text { Cereal harvesting month } \\
\text { (16 July-15 August) }\end{array}$ & $\begin{array}{r}162 \pm 79 \\
n=29\end{array}$ & $\begin{array}{c}286 \pm 111 \\
n=26\end{array}$ & $t=6.33, \mathrm{df}=25, p<0.001$ \\
\hline $\begin{array}{l}\text { Month after cereal har- } \\
\text { vesting and before shooting } \\
\text { (16 August-15 September) }\end{array}$ & $\begin{array}{r}140 \pm 63 \\
n=38\end{array}$ & $\begin{array}{r}292 \pm 82 \\
n=35\end{array}$ & $t=11.45, \mathrm{df}=34, p<0.001$ \\
\hline Between-month statistics & $t=0.45, \mathrm{df}=26, p=0.65$ & $t=0.88, \mathrm{df}=22, p=0.39$ & \\
\hline
\end{tabular}

Monthly variations in the diurnal use of space

Month-by-month comparisons were carried out using non-parametric paired tests to study variations of the mean resting range size. It varied little from one month to the next during late spring to late autumn (Fig. 3). Only two small changes can be distinguished: (1) a decrease between the cereal-harvesting month and the next, which may be an artefact (MCP determined by a smaller number of fixes for the 16 August-15 September month); (2) a small increase in range between the opening month of the shooting season and the next. Several hares moved long distances during this month.

DDD variations from May to December are more demonstrative. When examining the rough data, hares seem to have used closer-situated forms during cereal harvesting and the month after (Fig. 3). Month-by-month paired tests confirm this tendency: hares had significantly higher DDD during the month preceding cereal harvesting than during the two following months. Just after the cereal harvest DDD was also significantly smaller than during the last month.

Five hares (two young males, one adult male, two adult females) among which three newly-marked animals, could regularly be monitored in February and March. The ten monthly home range areas that could therefore be determined $(\bar{x}=71$ ha, MCP method, 22 fixes by range) are much larger than the summer and autumn 

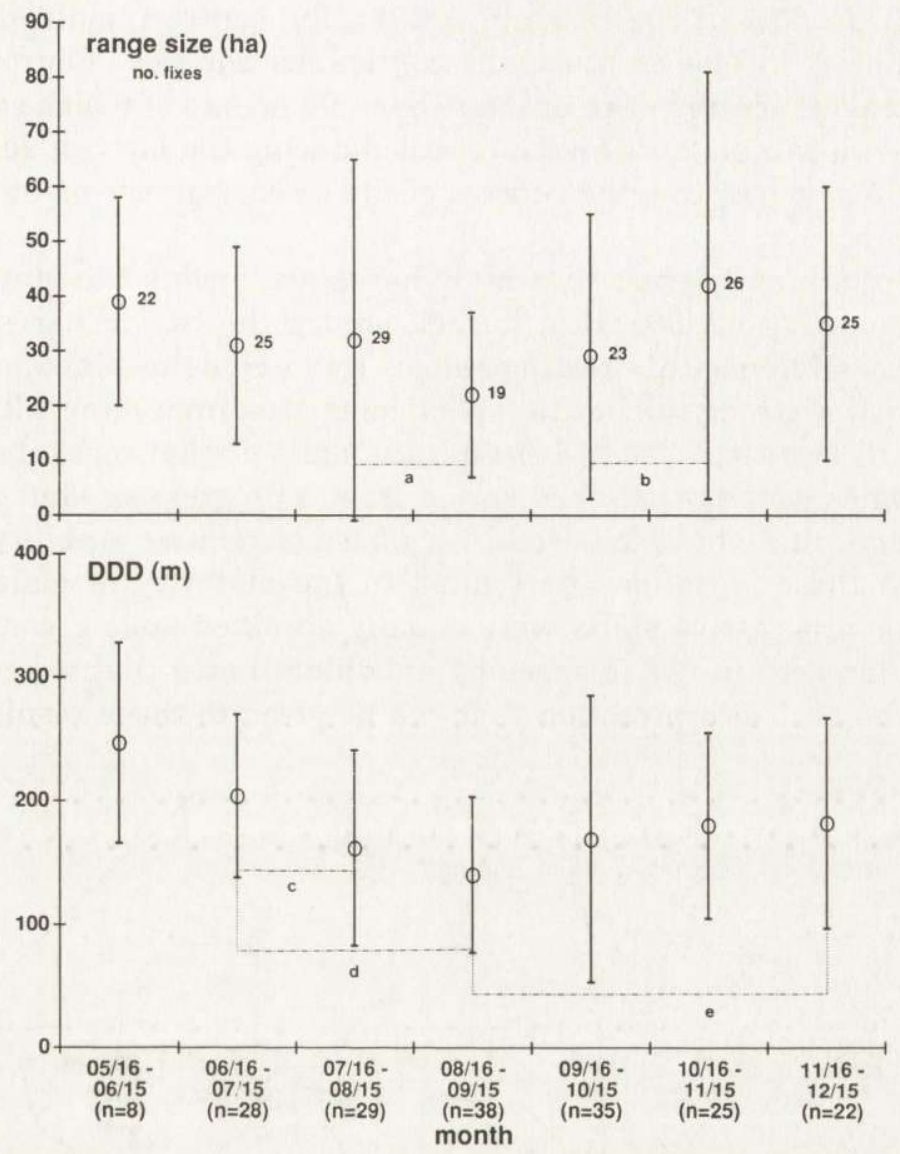

Fig. 3. Monthly evolution of the diurnal use of space by hare: variations in range sizes ( \pm SD) computed by MCP method and mean distance between two successive-day resting places (DDD) for the same hares. The lower-case letters mark the significantly different values: (a) Wilcoxon test: $n=26, p<0.05$, (b) Wilcoxon test: $n=25, p<0.05$, (c) Student paired $t$-test: $t=2.92, \mathrm{df}=24, p<0.01$, (d) Student paired $t$-test: $t=2.58, \mathrm{df}=21, p<0.05$, (e) Student paired $t$-test: $t=2.13, \mathrm{df}=19, p<0.05$.

ranges but they cannot be compared statistically since these scarse data are not totally paired nor independent.

\section{Fidelity to a resting range}

We noted earlier that long-period home ranges often were much larger than short-period ones. This could correspond to a progressive shift over time of the hare home range. To get a better idea of the stability of the home range location, we studied the consecutive shifts of day range centres on a monthly scale. On average some $200 \mathrm{~m}$ separated two successive monthly centres, i.e. approximately the value of the mean distance between resting places (see DDD values in Table 
4 and Fig. 3). In $55 \%$ of the cases $(n=136)$, the centre remained in the same square or shifted to one of the eight contiguous squares. Fourteen distances between successive centres were greater than $500 \mathrm{~m}$, two of which exceeding 1000 $\mathrm{m}$. The longest mean distances were recorded during the harvest season, with an average of $300 \mathrm{~m}$ separating the centres of the cereal harvest-month from that of the next month.

These results may suggest that most hares are inclined to stay in the same resting area for long periods. But, in fact, among the twelve hares for which at least five successive monthly resting ranges could be determined, only the three females showed a strong fidelity to a particular area from June till November or December with less than $300 \mathrm{~m}$ between the most distant monthly centres (Fig. 4). Among males, activity patterns varied from a progressive shift of the resting range to a large movement followed by a phase of relative stability. There is no evidence that these variations be related to the maturity of males since large movements or progressive shifts were equally observed among young and adult. The large differences in use of space by individual hares that we evoked earlier, probably is the best interpretation that can be given to these results.

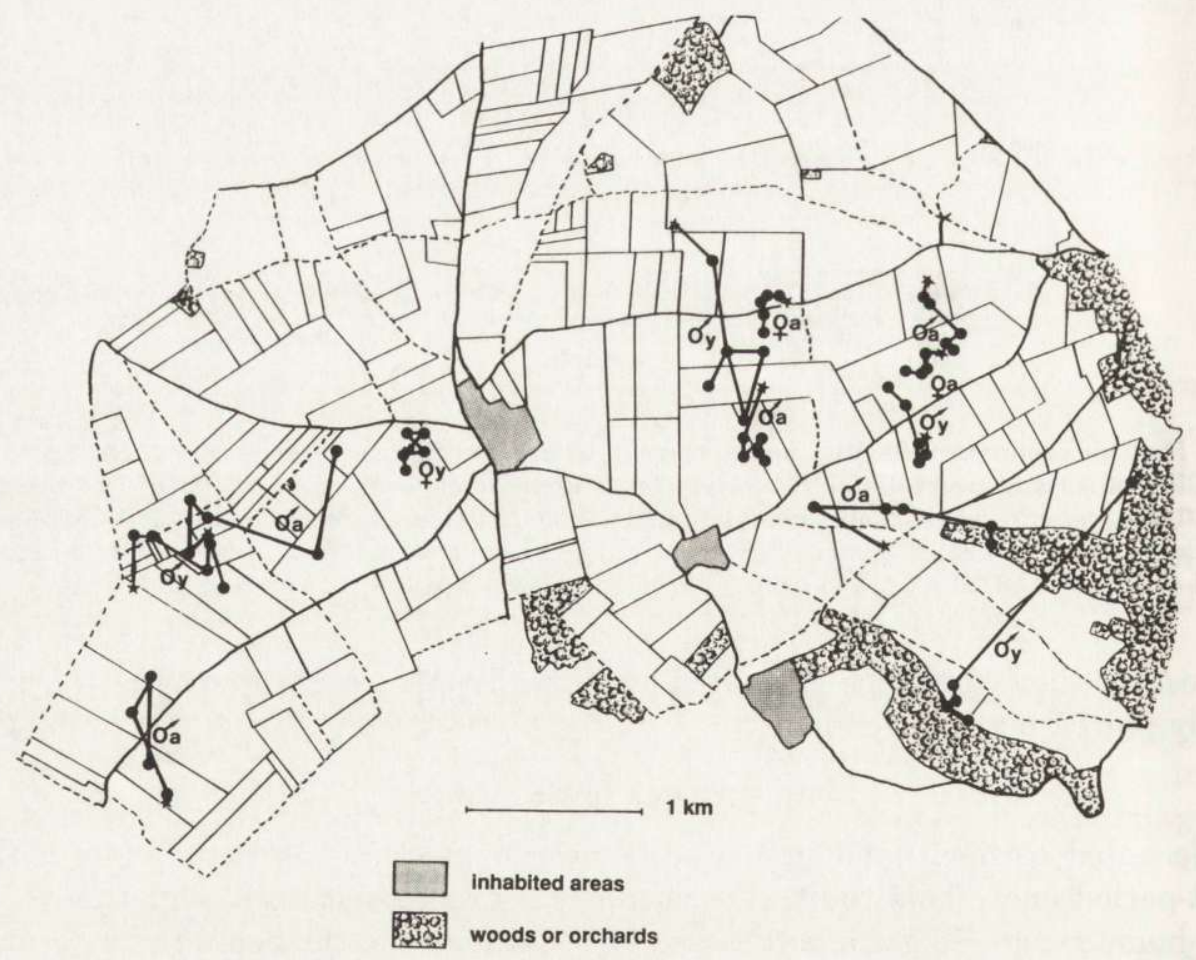

Fig. 4. Successive positions of the monthly resting range centres of the hares (y - young, a - adult) tracked during at least five months from 16 June. The stars indicate the range centres of the first month. 


\section{Discussion}

Although our aim was not to compare different radiotracking data-analysis methods, we did use several approaches as recommended by Harris et al. (1990) to obtain more reliable results comparable with those already published. Theoretical studies have shown that different methods can give highly variable range areas (e.g. Boulanger and White 1990). In fact, the estimates given by both methods that we intensively used (MCP and Kernel smoothing) much differed for some animals, but the mean range sizes were consistent. We did not test the independence of successive fixes, which always is an assumption in range area calculations (Worton 1987, White and Garrott 1990, Harris et al. 1990). Following Swihart and Slade (1985), we considered that locating hares only once per $24 \mathrm{~h}$ at various hours minimised this risk. Anyway, non-parametric methods should be less sensitive to a violation of this assumption (Harris et al. 1990).

Before comparing our results to others, we must emphasize that, as recalled by Harris et al. (1990), the definition of a home range plainly depends on the length of study. Our results for long-periods significantly differed from those determined for a few months. In the same way, using Tapper and Barnes (1986) data, we found a nearly significant correlation coefficient $(r=0.5, p=0.06, n=$ 15) between home range size and length of study. Of course the number of fixes, and, in particular, night fixes, is likely to determine range size. But, considering the analysis method that has been used in both cases, this is probably not the main explanation. This leads us to differ with Broekhuizen and Maaskamp (1982), who thought that hares cover a large part of their total home range within a few weeks. Our results could be explained by the hares progressively using new fields that bring them new food or good resting places after some agricultural operations or vegetation growth. The slight and occasionnal shifts of the activity centres that we observed can be interpreted to result from this behaviour. The comparison with other published data must therefore consider the length of the study period.

Our range sizes obtained for long periods are smaller than Pielowski's (1972). In fact, his method of calculation applied to data collected on chased animals assumed range was circular which gave a biased estimate of home range area. However, our home range sizes are larger than those obtained in other countries. For example, Broekhuizen and Maaskamp (1982) and Kovacs and Buza (1988) obtained mean home range sizes of 29 to 45 ha, but they used a much shorter tracking period which could explain at least part of the difference. For similar periods of time our data would have given mean areas of 60 to 70 ha. Parkes (1984), who tracked five hares during a whole year, also obtained small areas, but his hares lived in a more homogeneous landscape and probably suffered less from human disturbances than ours. Our data are strikingly similar to Tapper and Barnes' (1986) when harmonic-mean calculations are compared giving exactly the same mean range size of 38 ha with $90 \%$ of the fixes. One might have expected larger areas in our study since we tracked for longer periods (on average less than 
four months in the English study) and their landscape diversity was probably greater, although it was not precisely described. Hewson and Hinge (1990) in a mountain hare Lepus timidus study obtained areas similar to ours using the MCP method. On the other hand, the harmonic-mean analysis method shows that European hares use a more restricted $90 \%$ core area than do mountain hares (38 ha and 63 ha respectively). This means that the latter visit their whole home range more uniformly.

If day and night ranges of mountain hares, which correspond to well-defined types of vegetation, little overlap (Hewson and Hinge 1990), this does not seem to be the case for the European hare in our study area. On the contrary, there is generally an important overlap of resting ranges and activity areas. In fact, hares often feed and rest in the same or in contiguous fields. However, in the latter case, the situation most often observed by us (e.g. Fig. 1), is not as distinct as the case in Tapper and Barnes (1986, Fig. 4), where a habitat boundary clearly separates resting and activity areas. This sometimes occurred in our study but resting and activity areas were usually spatially mixed. However, resting and activity centres were distinct. The mean distance we found between them $(260 \mathrm{~m})$ and the DND (300-400 m, Tables 1 and 4) are similar to the distances Homolka (1985) determined by faecal analyses.

When hares fed and rested in the same field - which was often observed in summer for hares living in sugar beet - they rarely fed in the same place where they were resting some hours before. We found, like Pepin and Cargnelutti (1987) in two reared leverets, that a resting place and the susbsequent night location were, almost always, at least one hundred meters apart. Perhaps this is an instinctive behaviour evolved to escape predation. Hares move to and from their forms in such a way as to minimize the risk of predation (Flux 1981).

As in other studies (see in particular Marboutin et al. 1991, Tapper and Barnes 1986), we found a high variability in the use of space between individuals. Thus it is very difficult to obtain statistically significant differences even when a large number of animals are monitored. Nevertheless our differences were often very small. Contrary to Pielowski's (1972) findings on European hares we could not show any difference between sexes in range sizes and mean distances covered in the summer and autumn periods, although the breeding period from mating to nursing which could have caused variation in movement, was not over if we refer to other studies (Flux 1965, Hewson and Taylor 1975, Tapper 1987). Probably, there is a difference between sexes in fidelity to a range, but the small number of marked hares prevented us from reaching an undoubted conclusion. No other differences could be shown between young of the year and adult hares. Broekhuizen and Maaskamp (1982) arrived at a similar conclusion. As a matter of fact, the young hares we monitored were old enough to behave as adults. Our data demonstrate that they have a similar ranging behaviour, although most of them probably differ from adults by their non-reproductive status - female hares born 
in early spring can reach sexual maturity in autumn (Flux 1967, Pepin 1977). There is no evidence of dispersal by young hares in our study.

We used multiple paired-tests to analyse the temporal alterations in range size and movements. Although the great number of tests we performed led to increase the type I error (rejection of the null hypothesis where it should be accepted), there is a strong presumption that cereal harvesting caused slight fluctuations in the day-time use of space. The increase in the standard deviation of the home range size at the end of July also suggests that hares did react to these disturbances. Habitat-use analysis (unpubl. data) shows that the cereal fields, avoided before harvesting for resting and feeding, become well used as stubble or ploughed stubble after harvest. The development of the use of space during this period, and particularly the significant decrease in overlap of day and night ranges, is the consequence of a gradual take-up in use of those stubble fields close to previous resting places. No large-scale effect of shooting could be shown, although a few distant movements were recorded after shooting on the area. However, in these cases the hares usually came back to their earlier resting place. Hence, if human activities in summer and autumn do cause disturbance to hares, - and perhaps this is why they had larger home ranges than they do in other habitat types - we did not find any generalized enlargement or shifts in home range specifically due to cereal harvesting or shooting.

The data we collected during late winter, i.e. after the beginning of the breeding season (Flux 1965), seemed to reveal a rather different pattern of use of space by hares, with larger monthly home ranges. Unfortunately, these data were recorded for very few hares and further studies are necessary to improve our knowledge of use of space at this period of the year.

In conclusion, our work shows that the hares of the Paris Basin seem to behave in a way quite similar to those living in agricultural landscapes in other countries. Thus the heavy agricultural pressure found in our study area had little overall effect on their use of space. In particular, the disturbance caused by the harvest, which affected nearly the whole study area for almost four months (from mid-July to the end of October), apparently had few consequences, and no serious ones on hare movements. Also, they survived very well through this period (Reitz and Léonard 1993).

Acknowledgments: We are greatly indebted to J. M. Vasseur and B. Baudoux, technician trainees, who recorded a significant part of the field data and to V. Dimeck and C. Verger who conducted the arduous task of tabulating data. We are grateful to the landowners, farmers and sportsmen who allowed us to mark and monitor the hares. Many thanks to L. Ellison, E. Marboutin, R. Peroux, B. Scherrer, E. Taran and anonymous referees for their helpful comments on previous versions.

\section{References}

Barnes R. F. W. and Tapper S. C. 1985. A method for counting hares by spotlight. J. Zool. Sci. A 206: 273-276. 
Boulanger J. G. and White G. C. 1990. A comparison of home-range estimators using Monte-Carlo simulation. J. Wild. Manage. 54: 310-315.

Broekhuizen S. and Maaskamp F. 1979. Age determination in the European hare (Lesus europaeus Pallas) in the Netherlands. Z. Säugetierk. 44: 162-175.

Broekhuizen S. and Maaskamp F. 1982. Movement, home range and clustering in the European hare (Lepus europaeus Pallas) in The Netherlands. Z. Säugetierk. 47: 22-32.

Dixon K. R. and Chapman J. A. 1980. Harmonic mean measure of animal activity areas. Ecology 61: 1040-1044.

Flux J. E. C. 1965. Timing of the breeding season in the Hare, Lepus europaeus Pallas, and Rabbit, Oryctolagus cuniculus (L.). Mammalia 29: 557-562.

Flux J. E. C. 1967. Reproduction and body weights of the hare Lepus europaeus Pallas, in New Zealand. N. Z. J. Sci. 10: 357-401.

Flux J. E. C. 1981. Field observations of behaviour in the genus Lepus. [In: Proceedings of the World Lagomorph Conference. K. Myers and C. D. MacInnes, eds]. University of Guelph, Ontario: 377-394.

Harris S., Cresswell W. J., Forde P. G., Trewhella W. J., Woollard T. and Wray S. 1990. Home range analysis using radio-tracking data - a review of problems and techniques particularly as applied to the study of mammals. Mammal Rev. 20: 97-123.

Hewson R. and Hinge M. D. C. 1990. Characteristics of the home range of mountain hares Lepus timidus. J. Appl. Ecol. 27: 651-666.

Hewson R. and Taylor M. 1975. Embryo counts and length of the breeding season in European hares in Scotland from 1960-1972. Acta theriol. 20: 247-254.

Homolka M. 1985. Spatial activity of hares (Lepus europaeus). Folia zool. 34: 217-226.

Kenward R. 1990. Ranges IV. Software for analysing animal location data. Institute of Terrestrial Ecology, Wareham U.K.: 1-33.

Kovacs G. and Buza C. 1988. Characteristics of the home range of the brown hare (Lepus europaeus Pallas) in a forested and in a large-scale cultivated agricultural habitat. 1. Size of the home range. Vadbiologia 88: 67-84.

Marboutin E., Benmergui M., Landry P. and Fiechter A. 1991. Distribution spatio-temporelle des gites diurnes chez le levraut (Lepus europaeus) sauvage et d'élevage. Gibier Faune Sauvage 8: 93-113.

Mohr C. O. 1947. Table of equivalent populations of North American small mammals. Am. Midl. Nat. 37: 223-249.

Parkes J. P. 1984. Home ranges of radio-telemetered hares (Lepus capensis) in a sub-alpine population in New Zealand: implications for control. Acta zool. fenn. 171: 279-281.

Pepin D. 1973. Recherche d'un critère d'âge chez le livère Lepus europaeus. Ann. Zool. Ecol. anim. 5: 271-281.

Pepin D. 1977. Phase finale du cycle de reproduction du livère, Lepus europaeus. Mammalia 41: 221-230.

Pepin D. and Birkan. M. 1981. Comparative total and strip-census estimates of hares and partridges. Acta Oecol. Oecol. Applic. 2: 151-160.

Pepin D. and Cargnelutti B. 1985. Dispersion et cantonnement de livères de repeuplement (Lepus europaeus). Biol. Behav. 10: 353-365.

Pepin D. and Cargnelutti B 1987. Développement de stratégies d'utilisation de l'espace et du temps lors de l'implantation en nature de Levrauts (Lepus europaeus) issus d'élevage. Gibier Faune Sauvage 4: 149-164.

Pielowski Z. 1972. Home range and degree of residence of the European hare. Acta theriol. 9: 93-103.

Reitz F. and Léonard Y. 1993. La survie estivale et automnale du livère d'Europe (Lepus europaeus) dans une plaine de grande culture du Bassin parisien. Gibier Faune Sauvage 10: 167-172.

Ricci J. C. 1983. Suivi d'un lâcher de lièvres d'importation (Lepus europaeus Pallas) au moyen de la radiotélémétrie: mortalité, dispersion et utilisation de l'espace. Acta Oecol. Oecol. Applic. 4: $31-46$. 
Slamecka J. 1991. The influence of oecological arrangements on brown hare population. [In: XXth Congress of the International Union of Game Biologists, Gödöllö. S. Csanyi and J. Ernhaft, eds]. University of Agricultural Sciences, Gödöllö, Hungary: 340-346.

Sokal R. R. and Rohlf F. J. 1981. Biometry. 2nd edition. W. H. Freeman and company, New York: $1-860$.

Swihart R. K. and Slade N. A. 1985. Influence of sampling interval on estimates of home-range size. J. Wildl. Manage. 49: 1019-1025.

Tapper S. 1987. The brown hare. Shire Publications Ltd, Aylesbury, U.K.: 1-24.

Tapper S. C. and Barnes R. F. W. 1983. A study of the causes of the decline in numbers of the brown hare (Lepus capensis) in Britain. [In: Proceedings from XVI IUGB congress]. Vysoké Tatry, Strbské Pleso, CSSR: 430-440.

Tapper S. C. and Barnes R. F. W. 1986. Influence of farming practice on the ecology of the brown hare (Lepus europaeus). J. Appl. Ecol. 23: 39-52.

Walhovd H. 1966. Reliability of age criteria for Danish hares (Lepus europaeus Pallas). Danish Rev. Game Biol. 4: 106-128.

White G. C. and Garrott R. A. 1990. Analysis of wildlife radio-tracking data. Academic Press, London: 1-383.

Worton B. J. 1987. A review of models of home range for animal movement. Ecol. Model. 38: 277-298.

Worton B. J. 1989. Kernel methods for estimating the utilization distribution in home-range studies. Ecology 70: 164-168.

Received 28 July 1993, accepted 5 March 1994. 